\title{
Repetitive subconcussive head impacts and changes in sensory processing for balance control
}

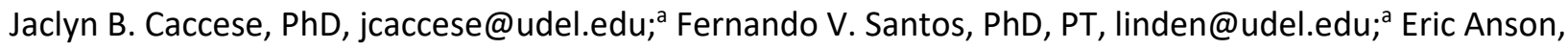
MPT, PhD, eric_anson@urmc.rochester.edu; ${ }^{b}$ Thomas A. Buckley, EdD, ATC, tbuckley@udel.edu; ${ }^{a}$ Felipe Yamaguchi, PT, felipeky@udel.edu; ${ }^{a}$ Mariana Gongora,PhD, marianagongora@gmail.com; John J. Jeka, PhD, jjeka@udel.edu

a University of Delaware, Department of Kinesiology and Applied Physiology, 540 S. College Ave., Newark, DE 19713, USA

${ }^{b}$ University of Rochester, Department of Otolaryngology, 2365 S. Clinton Ave., Suite 200, Rochester, NY 14618, USA

\section{Corresponding Author}

John J. Jeka, PhD

Address: 540 S. College Ave., Room 201T, Newark, DE 19713, USA

Email: jjeka@udel.edu

Phone: $302-831-4648$

\section{Abstract}

Background: Repetitive subconcussive head impacts (RHI) may be associated with current and future detrimental neurological effects. However, the effects of RHI on sensory processing for balance control is unknown and may have significant clinical implications if athletes are still participating in sport despite impairments. Research Question: Are there changes in sensory processing for balance control during standing and walking following RHI? Methods: Thirty healthy, adult, amateur soccer players (15 males, 15 females, $21.8 \pm 2.8$ years, $69.9 \pm 11.5 \mathrm{~kg}, 171.4 \pm 8.2 \mathrm{~cm}$ ) volunteered for the standing balance 
assessment (i.e., experiment 1). A distinct cohort of twenty healthy, adult, amateur soccer players (10 males, 10 females, $22.3 \pm 4.5$ years, $70.0 \pm 10.5 \mathrm{~kg}, 170.5 \pm 9.8 \mathrm{~cm}$ ) volunteered for the walking balance assessment (i.e., experiment 2). We used a repeated measures design across three time points (preheading, 0-hours post-heading, 24-hours post-heading). Participants were randomly assigned to an experimental (i.e., performed 10 soccer headers in 10 minutes) or a control group (i.e., did not perform any soccer heading between sessions). In experiment 1 , participants stood in a virtual reality cave while experiencing simultaneous perturbations to their visual, vestibular, and proprioceptive systems. In experiment 2, participants walked blindfolded along a foam walkway and experienced a vestibular perturbation on the second heel strike of the right foot. Changes in sensory processing were assessed using repeated measures ANOVAs. Results: There were no changes in sensory reweighting during experiment 1 and no changes in balance responses to the vestibular stimulus in experiment 2 .

Significance: Although the cumulative effects of RHI may result in later-life cognitive, behavioral, and mood impairments, a single episode of repeated soccer headers does not appear to be associated with acute impairments in sensory processing for balance control.

\section{Key Words}

concussion, mild traumatic brain injury (mTBI), postural control, sensorimotor, vestibular

\section{Introduction}

Chronic Traumatic Encephalopathy (CTE) is a neurodegenerative disease thought to be caused by repetitive brain trauma that can occur during contact sports and military participation. [1] While initially reported in individuals with history of multiple concussions, or mild traumatic brain injuries, CTE has more recently been identified in football players with no history of diagnosed concussions, but with history of exposure to repetitive subconcussive head impacts (RHI).[1] A subconcussive head impact is a mild head impact that does not result in acute clinical signs or symptoms of neurological dysfunction, 
but may cause neurological deficits when sustained repeatedly.[2] Biomechanical investigations of head impacts in American football and soccer have indicated that athletes at the collegiate level sustain high numbers of RHI ranging from several hundred to well over 1000 during the course of a season.[3-6] Yet, the effects of RHI on neurological function are poorly understood.[2,7-10]

Quantifying changes in neurological function following RHI has several challenges. Clinical measures may not be sensitive enough to identify changes in neurological function following RHI. Though neuroimaging (e.g., functional MRI, DTI) can identify functional impairments and changes in white matter microstructure, we do not understand the clinical implications of these measures.[11-15] Moreover, on-field RHI exposure varies greatly in terms of magnitude, timing, type, and location of impact.[3-6] Variability in RHI exposure likely contributes to conflicting results across studies. To gain an understanding of the neurological deficits of $\mathrm{RHI}$, we need sensitive measures of neurological function, while controlling for $\mathrm{RHI}$ exposure. An experimental paradigm using a series of soccer headers allows for control of RHI exposure.[16-21] This soccer heading paradigm has been used to understand the biomechanics of RHI and the effects of RHI on standing balance and biomarkers of head injury.[16-21] Humans require precise integration and modulation of visual, vestibular, and proprioceptive feedback to control balance during standing and walking. Visual and vestibular systems are vulnerable to disruption from concussion and may also be vulnerable to disruption from RHI.[22] Probing these sensory systems while standing and walking may allow us to identify subtle changes in neurological function following RHI. Hwang and colleagues developed an experimental paradigm to understand how sensory feedback is dynamically reweighted so that overall feedback remains suited to stabilizing upright stance.[23] To examine sensory reweighting, they simultaneously perturbed visual (using virtual reality), vestibular (using galvanic vestibular stimulation, GVS) and proprioceptive (using vibration) sensory modalities. Both intra-modal and inter-modal sensory reweighting occurred as the amplitude of 
visual input increased. This experimental paradigm can be used to examine the association between RHI and sensory reweighting.

Sensory modulation to balance has also been demonstrated during walking. GVS can be applied at different phases during locomotion and with varying amplitudes with little discomfort to the subject and with reduced concerns of adaptation.[24-26] Healthy adults respond to GVS applied during walking using a coordinated series of balance mechanisms. $[27,28]$ Assuming that the perturbation occurs at heel strike, healthy adults sequentially use three mechanisms: lateral ankle roll followed by foot placement change and finally modulation of push off in the trailing leg. $[27,28]$ The lateral ankle mechanism shifts the stance foot center of pressure (CoP) in the direction of the perceived fall by $\sim 2.5 \mathrm{~mm}$. [27,28] Foot placement modulation shifts the swing foot of the following step by $\sim 15 \mathrm{~mm}$ in the same direction. $[27,28]$ Finally, push off modulation adjusts the plantarflexion angle of the trailing leg to move the center of mass (CoM) in the direction opposite of the perceived fall.[28] Using these methods, this study aims to examine whether $\mathrm{RHI}$ affects sensory processing and subsequent balance control during standing and walking. We hypothesized immediately following the soccer heading paradigm individuals would have 1) impairments in sensory reweighting during standing and 2) diminished balance responses to GVS during walking.

\section{Methods}

\section{Participants}

Thirty soccer players (14 females, $21.8 \pm 2.8$ years, $69.9 \pm 11.5 \mathrm{~kg}, 171.4 \pm 8.2 \mathrm{~cm}$ ) volunteered for the standing balance assessment (i.e., Experiment 1). A distinct cohort of twenty soccer players (10 females, $22.3 \pm 4.5$ years, $70.0 \pm 10.5 \mathrm{~kg}, 170.5 \pm 9.8 \mathrm{~cm}$ ) volunteered for the walking balance assessment (i.e., Experiment 2). Potential participants were $18-35$ years old with at least 5 years of soccer heading experience. Exclusion criteria included: head, neck, or lower extremity injury in the previous six months; history of balance problems; taking medications affecting balance; neurological disorders; unstable 
cardiac or pulmonary disease; goalkeepers due to lack of routine soccer heading practice. The university institutional review board approved the study and participants provided written informed consent. Participants in each experiment were randomly assigned to a heading group (EXP) or control group (CON). The EXP performed a soccer heading paradigm (described below), while the CON did not perform soccer heading.

\section{Experimental Design}

We used a repeated measures design across three time points.[21] At each time point, participants completed either a standing balance assessment or a walking balance assessment (described below). The pre-heading session (PRE) was a baseline measurement. After 24h, the EXP performed 10 headers. The balance assessments were repeated immediately following the heading (POST-Oh) and 24h later (POST-24h).

\section{Soccer Heading Paradigm}

We used a soccer heading paradigm as an in-vivo model of repeated mild head impact.[17] We projected soccer balls (size 5, 450g, 8psi) using a JUGS soccer machine (JUGS Sports, Tualatin, OR); the initial velocity was $11.2 \mathrm{~m} / \mathrm{s}$, the angle of projection was $40^{\circ}$, and the distance to the participant was 12m.[16-21] The EXP performed 10 headers in 10 minutes, while CON did not perform soccer heading.

\section{Experiment 1 - Standing Balance Assessment}

We used an established paradigm for assessing sensory reweighting for standing balance (Figure 1).[23] Participants stood in a virtual reality cave (Bertec Corporation, Columbus, OH, USA), while experiencing simultaneous perturbations to visual, vestibular, and proprioceptive systems. Participants experienced four conditions: low amplitude visual scene translation with vibration and GVS (LVG), low amplitude visual scene translation without vibration but with GVS (LG), high amplitude visual scene translation with vibration and GVS (HVG), and high amplitude visual scene translation without vibration but with 
GVS (HG). Five trials for each condition were presented in random order for a twenty trials total. Trials lasted 135s.

The visual scene consisted of 500 randomly distributed white pyramids on a black background, which translated sinusoidally at $0.2 \mathrm{~Hz}$ in the anterior-posterior (AP) direction at two different amplitudes ( $0.2 \mathrm{~m}$ and $0.8 \mathrm{~m}$ for the low and high vision conditions, respectively). The proprioceptive sensory perturbation consisted of bilateral Achilles' tendon vibrations from two custom vibrators in a $1 \mathrm{~mm}$ displacement square-wave periodic stimulus at $0.28 \mathrm{~Hz}$. The vestibular sensory perturbation consisted of binaural-monopolar $\pm 1 \mathrm{~mA}$ sinusoidal GVS signal at $0.36 \mathrm{~Hz}$ using a neuroConn DC-Stimulator Plus (neuroCare Group, Munchen, Germany). Uncorrelated frequencies were chosen for each stimulus so independent responses to each sensory modality could be determined.

Bilateral kinematics were collected at $120 \mathrm{~Hz}$ using a twelve-camera motion analysis system (Qualisys, Goteborg, Sweden) and a marker set consisting of the temple, acromion, greater trochanter, lateral femoral condyle, lateral malleolus and first metatarsal head. The leg segment was defined by the AP displacement of the hip and ankle markers and the trunk segment by the AP displacement of the shoulder and hip markers. Gains and phases to each sensory modality were calculated. Gain is the amplitude of the output divided by the amplitude of the input at each driving frequency, calculated by the absolute value of the frequency response function, which is the cross spectral density divided by the power spectral density of the input.[23] Phase is a measure of the temporal relationship between the input and output; the output may lead the input or lag behind it.[23]

\section{Experiment 2 - Walking Balance Assessment}

Participants walked blindfolded along a 2-inch closed-cell foam walkway centered over two force plates (AMTI, Watertown, MA, USA). Participants initiated gait with their right foot and took six steps until they were instructed to stop. Binaural, bipolar GVS was delivered from two electrodes with $3.2 \mathrm{~cm}$ diameter (Axelgaard Manufacturing Co., Ltd, Fallbrook, CA, USA), placed on the mastoid processes. GVS was 
triggered on the second heel strike of the right foot and continued for $600 \mathrm{~ms}$. When triggered, a custom-made LabVIEW program (National instruments Inc., Austin, TX, USA) generated an analog voltage, which the neuroConn DC-Stimulator Plus transformed into a square wave of $1 \mathrm{~mA}$ current. In the GVS condition, the anode (LEFT) and cathode (RIGHT) created a perceived fall to the RIGHT. This perceived fall to the RIGHT creates an actual fall to the LEFT as a result of the actively generated motor response designed to prevent the perceived fall.[27] In the control condition, NO stimulation was delivered. Participants randomly repeated each of the two conditions 40 times, a total of 80 trials. Trials were excluded if the participant did not have a complete step on the force plate.

Bilateral kinematics were recorded at $120 \mathrm{~Hz}$ using a 6-degree of freedom marker set. Kinetic data were recorded at $1200 \mathrm{~Hz}$. Muscle activity was recorded at $1200 \mathrm{~Hz}$ using wireless electromyography (EMG; Trigno Wireless System, Delsys Inc., Natick, MA, USA). All data were analyzed in Visual 3D (CMotion, Inc., Germantown, MD, USA). Kinematic and kinetic data were filtered at 6 and $25 \mathrm{~Hz}$, respectively, using a zero-lag, low-pass Butterworth filter, and were analyzed from right heel strike (RON) to right toe off (ROFF). The EMG data were rectified and smoothed using a 50ms moving RMS. Variables for the three balance mechanisms were computed, including the stepping mechanism, the lateral ankle mechanism, and the push off mechanism. [28] Each of three balance mechanisms is described by a functional outcome measure, corresponding joint kinematics, and representative muscle activity (Table 1).[28] For all measures, the mean of the control trials was subtracted from each of the stimulus trials to estimate the response to the stimulus.[27,28] The average maximum activation across control strides was used to normalize EMG.

\section{Statistical Analysis}

Repeated measures ANOVAs were used to compare mean response variables between groups (i.e. EXP vs. CON) across different time points (i.e. PRE, POST-Oh, POST-24h). Outcome measures included gains 
and phases to each modality for Experiment 1 and the balance response variables for Experiment 2 . SPSS (IBM Corporation, Armonk, NY) was used for all statistical analyses; $\alpha=0.05$.

\section{Results}

Standing Balance Assessment - Leg AP Displacement

There were no changes in leg gain to vision (i.e. sessionXgroup effect; $F=0.798, P=0.455, \eta^{2}=0.028$ ), to GVS (F=0.246, $\left.P=0.782, \eta^{2}=0.009\right)$, or to vibration $\left(F=0.662, P=0.520, \eta^{2}=0.023\right)$ (Figure 1). In addition, there were no changes in sensory reweighting (i.e. sessionXconditionXgroup effect; vision, $F=0.430$, $P=0.858, \eta^{2}=0.015 ; G V S, F=0.763, P=0.600, \eta^{2}=0.027$; vibration, $F=0.430, P=0.653, \eta^{2}=0.015$ ) (Figure 1).

Leg segment displacements displayed phase leads of $\sim 25$ deg relative to GVS and of $\sim 50$ deg relative to vibration. Relative to the visual stimulus, leg phase was zero. There were no changes in leg phase to vision (i.e. sessionXgroup effect; $F=0.961, P=0.389, \eta^{2}=0.033$ ), to $G V S(F=0.427, P=0.654$, $\left.\eta^{2}=0.015\right)$, or to vibration $\left(F=0.375, P=0.689, \eta^{2}=0.013\right)$. In addition, there were no changes in phase across conditions (i.e. sessionXconditionXgroup effect; vision, $F=0.614, P=0.719, \eta^{2}=0.021 ; G V S, F=1.238$, $P=0.289, \eta^{2}=0.042 ;$ vibration, $\left.\mathrm{F}=0.153, P=0.858, \eta^{2}=0.005\right)$.

\section{Standing Balance Assessment - Trunk AP Displacement}

There were no changes in trunk gain to vision (i.e. sessionXgroup effect; $F=0.490, P=0.615, \eta^{2}=0.017$ ), to GVS $\left(F=0.205, P=0.815, \eta^{2}=0.007\right)$, or to vibration $\left(F=0.624, P=0.539, \eta^{2}=0.022\right)$. In addition, there were no changes in sensory reweighting (i.e. sessionXconditionXgroup effect; vision, $F=0.395, P=0.881$, $\eta^{2}=0.014 ;$ GVS, F=0.906, $P=0.492, \eta^{2}=0.031 ;$ vibration, $\left.\mathrm{F}=0.761, P=0.472, \eta^{2}=0.026\right)$.

Trunk segment displacements displayed phase leads of $\sim 30$ deg relative to GVS $\sim 45$ deg relative to vibration. Relative to the visual stimulus, trunk phase was zero. There were no changes in trunk phase to vision (i.e. sessionXgroup effect; $\left.F=1.257, P=0.292, \eta^{2}=0.043\right)$, to $G V S\left(F=0.656, P=0.523, \eta^{2}=0.023\right.$ ), or to vibration $\left(F=0.910, P=0.408, \eta^{2}=0.031\right)$. In addition, there were no changes in phase across conditions 
(i.e. sessionXconditionXgroup effect; vision, $\mathrm{F}=0.636, P=0.701, \eta^{2}=0.022 ; \mathrm{GVS}, \mathrm{F}=0.319, P=0.926$, $\eta^{2}=0.011 ;$ vibration, $\left.F=1.247, P=0.295, \eta^{2}=0.043\right)$.

Walking Balance Assessment

There were no significant groupXtime interactions for any of the balance response variables (lateral foot placement, $\mathrm{F}=0.563, P=0.574, \eta^{2}=0.030$; hip abduction, $\mathrm{F}=0.038, P=0.963, \eta^{2}=0.002$; integrated gluteus medius EMG, $\mathrm{F}=0.537, P=0.589, \eta^{2}=0.029$; integrated relative CoP, $\mathrm{F}=0.311, P=0.734, \eta^{2}=0.017$; ankle eversion, $\mathrm{F}=1.094, P=0.346, \eta^{2}=0.057$; integrated peroneus longus EMG, $\mathrm{F}=0.305, P=0.739, \eta^{2}=0.017$; step length, $\mathrm{F}=0.909, P=0.412, \eta^{2}=0.048$; ankle plantar flexion, $\mathrm{F}=0.610, P=0.549, \eta^{2}=0.033$; integrated gastrocnemius EMG, $\mathrm{F}=0.547, P=0.583, \eta^{2}=0.029$ ) (Table 2).

\section{Discussion}

While the acute effects of concussion have been characterized in the literature, the effects of RHI are poorly understood.[2,7-10] We examined the association between $\mathrm{RHI}$ and sensory processing for balance control during standing and walking. We hypothesized immediately following the soccer heading paradigm individuals would have 1) impairments in sensory reweighting during standing and 2) diminished balance responses to GVS during walking. Our findings did not support our hypotheses; there were no changes in sensory reweighting during standing or balance responses to GVS during walking. Despite concerns that $\mathrm{RHI}$ exposure through routine contact sport participation may result balance disturbances, our results do not support this association. Our findings are consistent with previous work suggesting repeated soccer heading has no effect on postural stability;[29-31] however, it should be noted that other studies were able to challenge the postural control system enough to elicit changes in standing balance.[16,21] We speculate contradictory results across studies may be attributed to the complexity/challenge of the balance task. For example, Haran and colleagues assessed participants in 6 virtual environment (VE) conditions: (1) stationary VE with stationary support surface, (2) in the dark with rotating support surface, (3) rotating VE with stationary support surface, (4) rotating VE with 
rotating support surface, (5) in the dark with stationary support surface, (6) stationary VE with rotating support surface, and only observed differences in condition 4, a particularly destabilizing condition.[16] Similarly, Hwang and colleagues noted decreased gain to GVS following RHI when participants were standing blindfolded on a foam surface; therefore, eliminating visual feedback and reducing proprioceptive feedback.[21] These studies elicited changes in standing balance, although translatability of these assessments to "real-world" balance tasks during which full sensory information is available remains an open question.

Despite growing public concern regarding the potentially adverse effects of $\mathrm{RHI}$, our results taken in the context of previous literature suggest there are few immediate changes in behavioral measures following $\mathrm{RHI}$, notwithstanding changes in neuroimaging and blood biomarkers.[10,32,33] In both animal and clinical studies, RHI have associated with Blood Brain Barrier dysfunction, abnormal neuro-metabolic and neuroinflammatory processes, as well as Tau aggregation.[10] In contrast, behavioral changes appear to be minimal. Caccese and colleagues used a multimodal clinical battery to examine changes in balance and neurocognitive function in collegiate women's soccer and men's American football players.[33] There were no changes in any of the measures from pre-season to postseason.[33] Additionally, Buckley and colleagues assessed changes in single-task and dual-task balance in American football players and non-contact athletes throughout a season; there were no changes for any of the dynamic balance tasks.[32] These findings are consistent with most studies which fail to identify short-term clinical differences related to $\mathrm{RHI}$; however, it is possible changes in neuroimaging and blood biomarkers manifest into long-term clinical impairments.

\section{Experiment 1}

In healthy adults, leg and trunk gain relative to vision decreases from low vision conditions to high vision conditions, which is intramodal reweighting.[23] In other words, as the visual scene amplitude increases, reliance on vision decreases (down-weighting). Similarly, leg and trunk gain relative to GVS stimulus and 
to vibration stimulus increases when visual amplitude increases, intermodal reweighting, to compensate for visual down-weighting. In our cohort, we see clear evidence of both intramodal and intermodal reweighting (Figure 1), suggesting that these individuals can perceive changes in sensory stimuli and generate appropriate sensorimotor responses. Although our standing balance assessment evaluated the dynamic modulation of three modalities, we did not observe changes in sensory reweighting after RHI. Our results differ from those of Hwang and colleagues, who reported diminished gain to GVS following soccer heading.[21] Importantly, the current protocol examined sensory reweighting, all sensory systems were perturbed simultaneously; whereas, Hwang and colleagues limited the use of vision with a blindfold and made proprioception constantly unreliable with a foam surface.[34,35] Perhaps when other sensory information is available (as in this experiment) participants can reweight sensory information to maintain upright stance, but under more extreme challenges when only vestibular information is available, participants experience diminished vestibular processing.

\section{Experiment 2}

In response to GVS stimulation during walking, healthy adults sway laterally in the direction away from the perceived fall.[27,28] Several corrective mechanisms are used to regain balance following this type of perturbation, including the lateral ankle mechanism, stepping mechanism, and push off mechanism.[28] This study was the first to quantify corrective balance mechanisms during GVS perturbed walking following RHI exposure. Although we observed small, systematic indications of each walking balance mechanism (i.e., participants responded to GVS perturbation), we did not observe changes in balance response variables following RHI (Table 2). There was substantial variability in how individuals use balance mechanisms (Table 2), which is consistent with previous research of individuals walking on a foam surface.[36] Although these complementary mechanisms allow for dynamic control in response to balance perturbations, the variability within and across individuals likely masked changes.

\section{Limitations}


Our interpretations are limited to effects of $\mathrm{RHI}$ on balance control during standing and walking and do not preclude changes in other neurological measures, such as cognition and mood. Future work should incorporate a multimodal battery of assessments. Although our soccer heading paradigm was designed to control RHI, 10 soccer headers may be insufficient to elicit balance deficits. RHI may cause neurological deficits that manifest over a career of repetitive head trauma and not after a single RHI exposure.

\section{Conclusion}

We examined whether sensory reweighting during standing and balance responses to GVS during walking were altered after controlled $\mathrm{RHI}$. Although the cumulative effects of $\mathrm{RHI}$ may result in later-life neurological deficits, a single episode of RHI was not associated with impairments in sensory processing for balance control. These findings have significant clinical implications; any impairments in balance as a result of RHI may predispose athletes to subsequent injury, so it is reassuring to find that there were no deficits in sensory processing for balance control during standing or walking.

\section{Conflict of interest statement}

The authors have no conflicts of interest to disclose.

\section{References}

[1] McKee AC, Cantu RC, Nowinski CJ, Hedley-Whyte ET, Gavett BE, Budson AE, et al. Chronic traumatic encephalopathy in athletes: progressive tauopathy after repetitive head injury. J Neuropathol Exp Neurol 2009;687:709-35.

[2] Bailes JE, Petraglia AL, Omalu BI, Nauman E, Talavage T. Role of subconcussion in repetitive mild traumatic brain injury: a review. J Neurosurg 2013;1195:1235-45. 
[3] Crisco JJ, Fiore R, Beckwith JG, Chu JJ, Brolinson PG, Duma S, et al. Frequency and location of head impact exposures in individual collegiate football players. J Athl Train 2010;456:549-59.

[4] Crisco JJ, Wilcox BJ, Beckwith JG, Chu JJ, Duhaime A, Rowson S, et al. Head impact exposure in collegiate football players. J Biomech 2011;4415:2673-8.

[5] Caccese JB, Lamond LC, Buckley TA, Kaminski TW. Reducing purposeful headers from goal kicks and punts may reduce cumulative exposure to head acceleration. Res Sports Med 2016;244:407-15.

[6] Lamond LC, Caccese JB, Buckley TA, Glutting J, Kaminski TW. Linear Acceleration in Direct Head Contact Across Impact Type, Player Position, and Playing Scenario in Collegiate Women's Soccer Players. J Athl Training 2018;532:115-21.

[7] Huber BR, Alosco ML, Stein TD, McKee AC. Potential long-term consequences of concussive and subconcussive injury. Phys Med Rehabil Clin N Am 2016;272:503-11.

[8] Belanger HG, Vanderploeg RD, McAllister T. Subconcussive blows to the head: a formative review of short-term clinical outcomes. J Head Trauma Rehabil 2016;313:159-66.

[9] Mainwaring L, Pennock KMF, Mylabathula S, Alavie BZ. Subconcussive head impacts in sport: a systematic review of the evidence. Int J Psychophysiol 2018;132:39-54.

[10] Hunter LE, Branch CA, Lipton ML. The neurobiological effects of repetitive head impacts in collision sports. Neurobiol Dis 2018 [Epub ahead of print].

[11] Talavage TM, Nauman EA, Breedlove EL, Yoruk U, Dye AE, Morigaki KE, et al. Functionally-detected cognitive impairment in high school football players without clinically-diagnosed concussion. J Neurotrauma 2014;314:327-38.

[12] Breedlove EL, Robinson M, Talavage TM, Morigaki KE, Yoruk U, O'Keefe K, et al. Biomechanical correlates of symptomatic and asymptomatic neurophysiological impairment in high school football. J Biomech 2012;457:1265-72. 
[13] Lipton ML, Kim N, Zimmerman ME, Kim M, Stewart WF, Branch CA, et al. Soccer heading is associated with white matter microstructural and cognitive abnormalities. Radiology 2013;2683:850-7.

[14] Stewart WF, Kim N, Ifrah C, Sliwinski M, Zimmerman ME, Kim M, et al. Heading frequency is more strongly related to cognitive performance than unintentional head impacts in amateur soccer players. Front Neurol 2018;9.

[15] Sollmann N, Echlin PS, Schultz V, Viher PV, Lyall AE, Tripodis Y, et al. Sex differences in white matter alterations following repetitive subconcussive head impacts in collegiate ice hockey players. Neuroimage Clin 2018;17:642-9.

[16] Haran FJ, Tierney R, Wright WG, Keshner E, Silter M. Acute changes in postural control after soccer heading. Int J Sports Med 2013;3404:350-4.

[17] Higgins MJ, Tierney RT, Caswell S, Driban JB, Mansell J, Clegg S. An in-vivo model of functional head impact testing in non-helmeted athletes. Proc Inst Mech Eng P J Sport Eng Technol 2009;2233:117-23.

[18] Dorminy M, Hoogeveen A, Tierney RT, Higgins M, McDevitt JK, Kretzschmar J. Effect of soccer heading ball speed on S100B, sideline concussion assessments and head impact kinematics. Brain Inj 2015;2910:1158-64.

[19] Caccese JB, Buckley TA, Tierney RT, Arbogast KB, Rose WC, Glutting JJ, et al. Head and neck size and neck strength predict linear and rotational acceleration during purposeful soccer heading. Sports Biomech 2018;17(4):462-476.

[20] Caccese JB, Buckley TA, Tierney RT, Rose WC, Glutting JJ, Kaminski TW. Sex and age differences in head acceleration during purposeful soccer heading. Res Sports Med 2018;261:64-74.

[21] Hwang S, Ma L, Kawata K, Tierney R, Jeka JJ. Vestibular dysfunction after subconcussive head impact. J Neurotrauma 2017;341:8-15.

[22] Valovich McLeod TC, Hale TD. Vestibular and balance issues following sport-related concussion. Brain Inj 2015;292:175-84. 
[23] Hwang S, Agada P, Kiemel T, Jeka JJ. Dynamic reweighting of three modalities for sensor fusion. PloS One 2014;91:e88132.

[24] Bent LR, McFadyen BJ, Inglis JT. Vestibular contributions during human locomotor tasks. Exerc Sport Sci Rev 2005;333:107-13.

[25] Fitzpatrick RC, Wardman DL, Taylor JL. Effects of galvanic vestibular stimulation during human walking. J Physiol 1999;5173:931-9.

[26] Fitzpatrick RC, Day BL. Probing the human vestibular system with galvanic stimulation. J Appl Physiol 2004;966:2301-16.

[27] Reimann H, Fettrow TD, Thompson ED, Agada P, McFadyen BJ, Jeka JJ. Complementary mechanisms for upright balance during walking. PloS One 2017;122:e0172215.

[28] Reimann H, Fettrow T, Thompson ED, Jeka JJ. Neural control of balance during walking. Front Physiol 2018;9.

[29] Broglio SP, Guskiewicz KM, Sell TC, Lephart SM. No acute changes in postural control after soccer heading. Br J Sports Med 2004;385:561-7.

[30] Schmitt DM, Hertel J, Evans TA, Olmsted LC, Putukian M. Effect of an acute bout of soccer heading on postural control and self-reported concussion symptoms. Int J Sports Med 2004;2505:326-31.

[31] Caccese JB, Buckley TA, Tierney RT, Rose WC, Glutting JJ, Kaminski TW. Postural Control Deficits After Repetitive Soccer Heading. Clin J Sport Med 2018 [Epub ahead of print].

[32] Buckley TA, Oldham JR, Watson DJ, Murray NG, Munkasy BA, Evans KM. Repetitive Head Impacts in Football Do Not Impair Dynamic Postural Control. Med Sci Sports Exerc 2018 [Epub ahead of print]. [33] Caccese JB, Best C, Lamond LC, DiFabio M, Kaminski TW, Watson D, et al. Effects of Repetitive Head Impacts on a Concussion Assessment Battery. Med Sci Sports Exerc 2019 [Epub ahead of print].

[34] Cohen HS, Kimball KT. Usefulness of some current balance tests for identifying individuals with disequilibrium due to vestibular impairments. J Vestib Res 2008;185, 6:295-303. 
bioRxiv preprint doi: https://doi.org/10.1101/648857; this version posted May 30, 2019. The copyright holder for this preprint (which was not certified by peer review) is the author/funder. All rights reserved. No reuse allowed without permission.

[35] Anson E, Bigelow RT, Studenski S, Deshpande N, Agrawal Y. Failure on the Foam Eyes Closed Test of Standing Balance Associated With Reduced Semicircular Canal Function in Healthy Older Adults. Ear Hear 2019;402:340-4.

[36] MacLellan MJ, Patla AE. Adaptations of walking pattern on a compliant surface to regulate dynamic stability. Exp Brain Res 2006;1733:521-30. 
Table 1. Definition of mechanisms used for balance control during walking. ${ }^{30}$

\begin{tabular}{|c|c|c|}
\hline $\begin{array}{c}\text { Balance } \\
\text { Mechanism }\end{array}$ & Variable & Definition \\
\hline \multicolumn{3}{|r|}{ Stepping Mechanism } \\
\hline $\begin{array}{l}\text { Functional } \\
\text { Outcome }\end{array}$ & $\begin{array}{c}\text { Foot Placement } \\
\text { Change }\end{array}$ & $\begin{array}{l}\text { Foot placement is the } \mathrm{M} / \mathrm{L} \text { position of the swing leg relative } \\
\text { to the stance leg at heel strike, and foot placement change } \\
\text { is the difference between a stimulus and the average of the } \\
\text { control. }\end{array}$ \\
\hline Joint Kinematics & $\begin{array}{l}\text { Hip Abduction } \\
\text { Change }\end{array}$ & $\begin{array}{l}\text { Abduction/adduction angle of the swing leg hip at the first } \\
\text { post-stimulus heel strike, with the average over the control } \\
\text { steps subtracted. }\end{array}$ \\
\hline Muscle Activity & $\begin{array}{l}\text { Integrated Gluteus } \\
\text { Medius EMG } \\
\text { Change }\end{array}$ & $\begin{array}{l}\text { Glut Med EMG of the swing leg, with the average over the } \\
\text { control steps subtracted, then integrated over the first } \\
\text { post-stimulus swing phase. }\end{array}$ \\
\hline \multicolumn{3}{|c|}{ Lateral Ankle Mechanism } \\
\hline $\begin{array}{l}\text { Functional } \\
\text { Outcome }\end{array}$ & $\begin{array}{l}\text { Integrated Relative } \\
\text { CoP Change }\end{array}$ & $\begin{array}{c}\mathrm{M} / \mathrm{L} \text { position of the CoP relative to the CoM, with the } \\
\text { average over the control steps subtracted, then integrated } \\
\text { over the first post-stimulus swing phase. }\end{array}$ \\
\hline Joint Kinematics & $\begin{array}{l}\text { Ankle Eversion } \\
\text { Change }\end{array}$ & $\begin{array}{l}\text { Eversion/inversion angle of the stance leg ankle at the first } \\
\text { post-stimulus heel strike, with the average over the control } \\
\text { steps subtracted. }\end{array}$ \\
\hline Muscle Activity & $\begin{array}{l}\text { Integrated } \\
\text { Peroneus Longus } \\
\text { EMG Change } \\
\end{array}$ & $\begin{array}{c}\text { Peroneus longus EMG of the stance leg, with the average } \\
\text { over the control steps subtracted, then integrated over the } \\
\text { first post-stimulus swing phase. }\end{array}$ \\
\hline \multicolumn{3}{|r|}{ Push Off Mechanism } \\
\hline $\begin{array}{l}\text { Functional } \\
\text { Outcome }\end{array}$ & Step Length Change & $\begin{array}{c}\text { A/P position of the swing leg relative to the stance leg at } \\
\text { heel strike, with the average over the control steps } \\
\text { subtracted. }\end{array}$ \\
\hline Joint Kinematics & $\begin{array}{l}\text { Ankle } \\
\text { Plantarflexion } \\
\text { Change }\end{array}$ & $\begin{array}{l}\text { Plantarflexion/dorsiflexion angle of the stance leg ankle at } \\
\text { the first post-stimulus push off, with the average over the } \\
\text { control steps subtracted. }\end{array}$ \\
\hline Muscle Activity & $\begin{array}{l}\text { Integrated } \\
\text { Gastrocnemius } \\
\text { EMG Change }\end{array}$ & $\begin{array}{l}\text { Gastrocnemius EMG of the stance leg, with the average } \\
\text { over the control steps subtracted, then integrated over the } \\
\text { first post-stimulus double-stance phase. }\end{array}$ \\
\hline
\end{tabular}


Table 2. Balance response variables during the walking balance assessment for each group (i.e., CON, EXP) across time (i.e., PRE, POST-Oh, POST-24h). Data represent mean \pm standard deviation.

\begin{tabular}{|c|c|c|c|c|}
\hline OUTCOME & GROUP & PRE & POST-Oh & POST-24h \\
\hline \multicolumn{5}{|c|}{ Stepping Mechanism } \\
\hline \multirow{2}{*}{ Foot Placement Change (m) } & CON & $0.030 \pm 0.017$ & $0.030 \pm 0.014$ & $0.025 \pm 0.017$ \\
\hline & EXP & $0.034 \pm 0.024$ & $0.033 \pm 0.018$ & $0.022 \pm 0.009$ \\
\hline \multirow{2}{*}{ Hip Abduction Change (deg) } & CON & $-1.146 \pm 0.677$ & $-1.202 \pm 0.820$ & $-0.938 \pm 0.714$ \\
\hline & EXP & $-0.753 \pm 0.813$ & $-0.869 \pm 1.127$ & $-0.502 \pm 0.801$ \\
\hline \multirow{2}{*}{$\begin{array}{l}\text { Integrated Gluteus Medius EMG Change } \\
\text { (normalized*s) }\end{array}$} & CON & $-0.002 \pm 0.007$ & $-0.005 \pm 0.003$ & $-0.005 \pm 0.010$ \\
\hline & EXP & $-0.002 \pm 0.009$ & $-0.001 \pm 0.006$ & $-0.004 \pm 0.005$ \\
\hline \multicolumn{5}{|c|}{ Lateral Ankle Mechanism } \\
\hline \multirow{2}{*}{ Integrated Relative CoP Change (m*s) } & CON & $0.002 \pm 0.002$ & $0.001 \pm 0.002$ & $0.002 \pm 0.001$ \\
\hline & EXP & $0.003 \pm 0.003$ & $0.002 \pm 0.002$ & $0.003 \pm 0.002$ \\
\hline \multirow{2}{*}{ Ankle Eversion Change (deg) } & CON & $5.606 \pm 2.801$ & $5.467 \pm 3.183$ & $4.217 \pm 2.604$ \\
\hline & EXP & $8.199 \pm 2.608$ & $6.339 \pm 1.710$ & $5.510 \pm 3.030$ \\
\hline \multirow{2}{*}{$\begin{array}{l}\text { Integrated Peroneus Longus EMG Change } \\
\text { (normalized*s) }\end{array}$} & CON & $-0.057 \pm 0.043$ & $-0.058 \pm 0.049$ & $-0.062 \pm 0.049$ \\
\hline & EXP & $-0.089 \pm 0.052$ & $-0.080 \pm 0.047$ & $-0.076 \pm 0.046$ \\
\hline \multicolumn{5}{|c|}{ Push Off Mechanism } \\
\hline \multirow{2}{*}{ Step Length Change (m) } & CON & $0.007 \pm 0.012$ & $0.007 \pm 0.014$ & $0.008 \pm 0.007$ \\
\hline & EXP & $0.011 \pm 0.007$ & $0.011 \pm 0.012$ & $0.006 \pm 0.008$ \\
\hline \multirow{2}{*}{ Ankle Plantarflexion Change (deg) } & CON & $0.001 \pm 0.009$ & $0.001 \pm 0.005$ & $0.001 \pm 0.007$ \\
\hline & EXP & $-0.002 \pm 0.013$ & $-0.005 \pm 0.009$ & $-0.002 \pm 0.008$ \\
\hline \multirow{2}{*}{$\begin{array}{l}\text { Integrated Gastrocnemius EMG Change } \\
\text { (normalized*s) }\end{array}$} & CON & $-0.215 \pm 3.073$ & $-0.284 \pm 2.456$ & $-0.239 \pm 1.849$ \\
\hline & EXP & $-1.353 \pm 2.955$ & $-1.648 \pm 2.455$ & $-0.532 \pm 3.673$ \\
\hline
\end{tabular}




\section{Figure Legends}

Figure 1. Set up for the standing balance assessment. Participants stood in a virtual reality while experiencing simultaneous perturbations to their visual, vestibular, and proprioceptive systems.

Figure 2. AP Leg (solid lines) and trunk (dashed lines) displacement gain to vision, gain to GVS, gain to vibration during the standing balance assessment. Lines represent group means \pm standard error. Participants experienced four conditions: low amplitude visual scene translation with vibration and GVS (LVG), low amplitude visual scene translation without vibration but with GVS (LG), high amplitude visual scene translation with vibration and GVS (HVG), and high amplitude visual scene translation without vibration but with GVS (HG). 


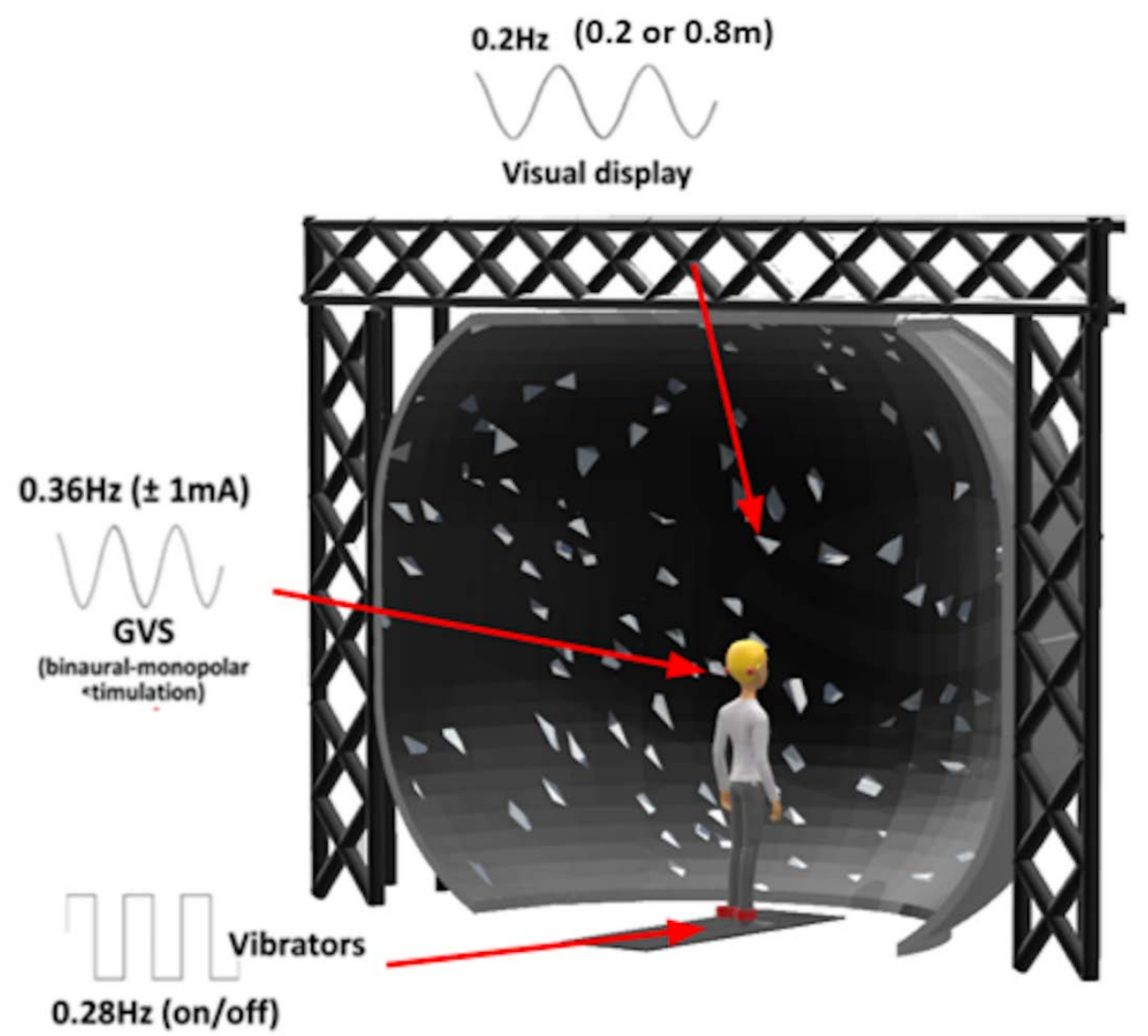



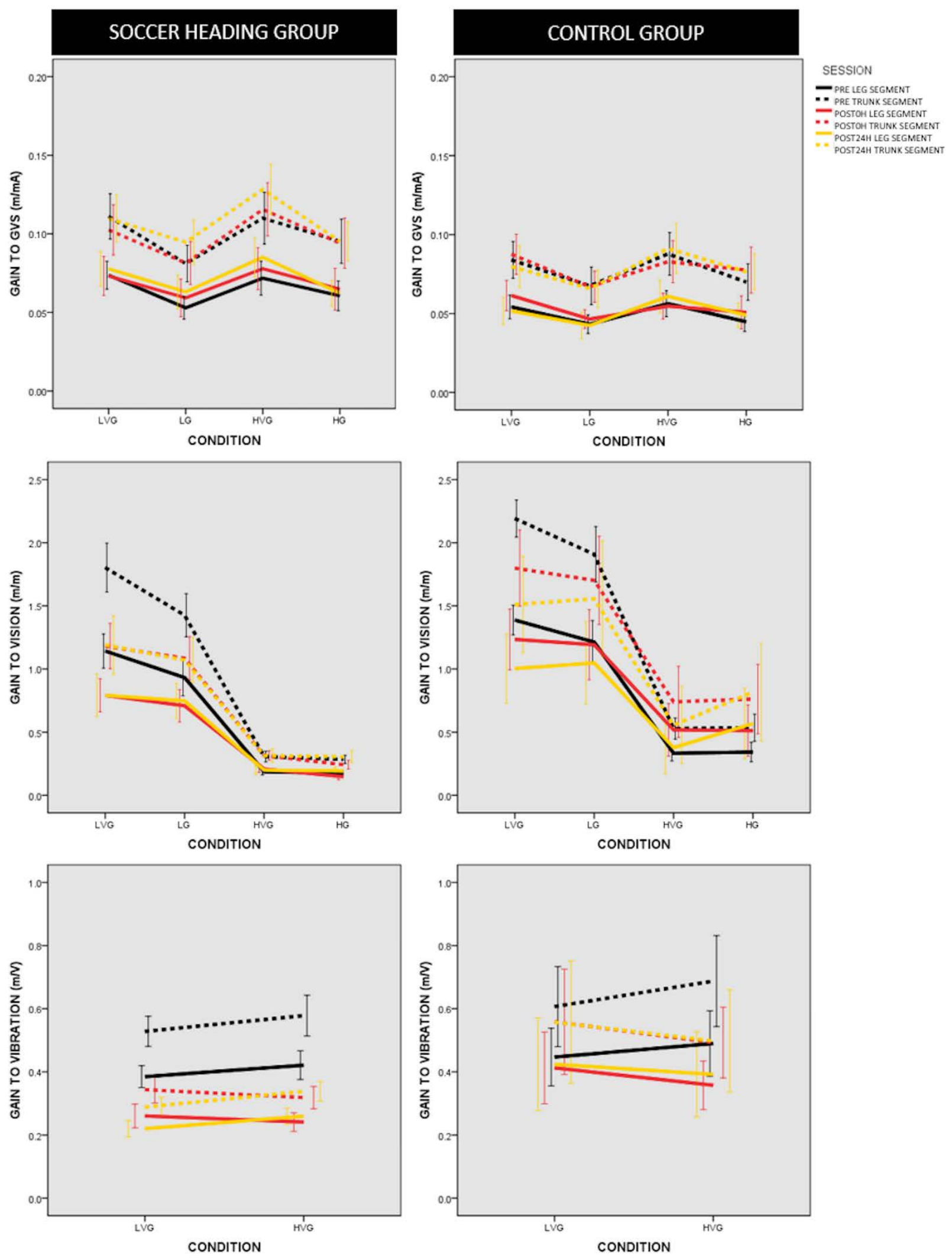